Article

\title{
An Electrochemical Sensor Based on a Nitrogen-Doped Carbon Material and PEI Composites for Sensitive Detection of 4-Nitrophenol
}

\author{
Xue Nie ${ }^{1}\left(\mathbb{D}\right.$, Peihong Deng ${ }^{1, *}$, Haiyan Wang ${ }^{2}$ and Yougen Tang ${ }^{2, *}$ \\ 1 Key Laboratory of Functional Metal-Organic Compounds of Hunan Province, Key Laboratory of Functional \\ Organometallic Materials of Hunan Provincial Universities, College of Chemistry and Material Science, \\ Hengyang Normal University, Hengyang 421008, China; hynuniexue@126.com \\ 2 College of Chemistry and Chemical Engineering, Central South University, Changsha 410083, China; \\ wanghy419@csu.edu.cn \\ * Correspondence: dph1975@163.com (P.D.); ygtang@csu.edu.cn (Y.T.); Tel.: +86-07318830886 (Y.T.); \\ Fax: +86-07318879616 (Y.T.)
}

check for updates

Citation: Nie, X.; Deng, P.; Wang, H.; Tang, Y. An Electrochemical Sensor Based on a Nitrogen-Doped Carbon Material and PEI Composites for Sensitive Detection of 4-Nitrophenol. Nanomaterials 2022, 12, 86. https:// doi.org/10.3390/nano12010086

Academic Editor: Silvia Scalese

Received: 22 November 2021

Accepted: 23 December 2021

Published: 29 December 2021

Publisher's Note: MDPI stays neutral with regard to jurisdictional claims in published maps and institutional affiliations.

Copyright: () 2021 by the authors. Licensee MDPI, Basel, Switzerland. This article is an open access article distributed under the terms and conditions of the Creative Commons Attribution (CC BY) license (https:// creativecommons.org/licenses/by/ $4.0 /)$.

\begin{abstract}
A glassy carbon electrode (GCE) was modified with nitrogen-doped carbon materials (NC) and polyethyleneimine (PEI) composites to design an electrochemical sensor for detecting 4-nitrophenol (4-NP). The NC materials were prepared by a simple and economical method through the condensation and carbonization of formamide. The NC materials were dispersed in a polyethyleneimine (PEI) solution easily. Due to the excellent properties of NC and PEI as well as their synergistic effect, the electrochemical reduction of the 4-NP on the surface of the NC-PEI composite modified electrode was effectively enhanced. Under the optimized conditions, at $0.06-10 \mu \mathrm{M}$ and 10-100 $\mu \mathrm{M}$ concentration ranges, the NC-PEI/GCE sensor shows a linear response to 4-NP, and the detection limit is $0.01 \mu \mathrm{M}$ (the signal-to-noise ratio is three). The reliability of the sensor for the detection of 4-NP in environmental water samples was successfully evaluated. In addition, the sensor has many advantages, including simple preparation, fast response, high sensitivity and good repeatability. It may be helpful for potential applications in detecting other targets.
\end{abstract}

Keywords: nitrogen-doped carbon material; polyethyleneimine; 4-nitrophenol; voltammetric detection; water sample

\section{Introduction}

With the development of industrialization, the harmful effects of phenolic compounds on the environment are more and more serious. Phenolic compounds are the products of many industrial processes, which are often released into the environment, and exist in soil and wastewater at the same time. Among all kinds of phenolic compounds, 4-nitrophenol (4-NP) is one of the priority organic pollutants listed by the U.S. Environmental Protection Agency [1]. The detection of 4-NP is an important topic in environmental pollution control. An important intermediate chemical, 4-NP is used in the production of pesticides, such as parathion, fenitrothion and methyl parathion [2]. However, 4-NP is highly toxic to mammals, fish and other aquatic organisms. It has been reported to be carcinogenic, mutagenic and cytoembryotoxic [3]. Therefore, the monitoring of 4-NP in the environment has been of wide concern, and a variety of analytical methods have been reported. At present, the analytical techniques used, such as chemiluminescence [4], fluorescence [5], high-performance liquid chromatography [6], capillary zone electrophoresis [7], gas chromatography-mass spectrometry [8], etc., often require complex sample pretreatment, well-trained technicians, expensive instruments and poisonous solvents.

In recent years, due to its advantages of eco-friendliness, high sensitivity, good selectivity and low cost, an electrochemical method has been widely used in the determination 
of pollutants, small biomolecules, food additives and heavy metal ions [9-19]. A molecule with high electrochemical activity, 4-NP can be easily reduced in the process of an electrochemical reaction. Therefore, various electrochemical sensors for 4-NP detection have been proposed [3,20-27] Although there are many kinds of electrochemical sensors for determining 4-NP, most of the electrochemical sensors for 4-NP detection are limited due to the complex electrode preparation, long response time, in-sufficient selectivity and poor stability. Therefore, it is still a challenge to prepare novel electrochemical sensors with excellent electrocatalytic properties by simple methods.

Carbon materials are widely used in electrochemical sensors because of their good conductivity, stable chemical properties and wide potential window. Nowadays, a variety of carbon materials with different structures have been successfully prepared, such as fullerene, carbon nanotubes, graphene, carbon nanofilms, carbon nanoparticles and porous carbon materials. Different structures of carbon materials lead to different surface properties, which makes them have a wide range of applications in materials, energy, electronic, biomedical and other fields. However, carbon has poor hydrophilicity and low surface activity, which seriously limits its functionalization and application. In recent years, the use of nitrogen-doped carbon materials to obtain unique properties has become a research hotspot [28-31]. When nitrogen is doped into carbon materials, it can not only enhance the conductivity of carbon materials, but also enhance the hydrophilicity and increase the number of surface active sites of carbon materials, which makes the nitrogen-doped carbon materials have more excellent physical and chemical properties [32]. At present, nitrogen-doped carbon materials are mainly prepared by an in situ doping method and post-treatment method. In the process of in situ doping, a special precursor containing a nitrogen atom is introduced into the synthesis of the carbon materials. After carbonization, the nitrogen atoms enter into the carbon materials. Commonly used nitrogen-containing precursors include polyimide [33], ethylenediamine [34], ionic liquid [35], melamine [36], polypyrrole [37], acetonitrile [38], urea [39] and nitrogen-containing metal organic framework compounds (MOFs) [40]. The post-treatment is to use some nitrogen-rich materials as nitrogen sources to modify the pre-synthesized carbon materials [41-43]. However, most of these nitrogen-doped carbon materials have a low nitrogen content and complicated synthesis steps.

In this study, a novel nitrogen-doped carbon material (NC) was prepared by using formamide as the nitrogen and carbon sources. Polyethyleneimine (PEI) is a kind of watersoluble polymer rich in amino groups, which is a good dispersant for the NC material into an aqueous solution. Therefore, this PEI-NC composite can be uniformly coated on the surface of a glassy carbon electrode. In addition, the composite film can be firmly attached to the electrode surface due to the excellent viscosity of the PEI, which greatly improves the repeatability and stability of the sensor. The electrochemical behavior of 4-NP on the PEI-NC/GCE was studied in detail. This PEI-NC/GCE sensor has been successfully applied for determining 4-NP in environmental water samples. Based on this, a simple and sensitive method for determining 4-NP is proposed.

\section{Experimental}

\subsection{Chemicals and Reagents}

Formamide (FA) and 4-nitrophenol (4-NP) were purchased from Sinopharm Chemical Reagent Co., Ltd., Shanghai, China. Polyethyleneimine (PEI) (25000) was obtained from Sigma-Aldrich (St. Louis, MO, USA). The 4-NP stock solution $(1.0 \mathrm{mM})$ was prepared by dissolving 4-NP into ethanol. Working solutions were freshly prepared by appropriate dilution of the stock solution. During the whole electrochemical measurements, $0.2 \mathrm{M}$ $\mathrm{H}_{2} \mathrm{SO}_{4}$ was used as the supporting electrolyte. All reagents were of analytical grade and used directly. All solutions were prepared with ultrapure water with resistivity $>18 \mathrm{M} \Omega \mathrm{cm}$. 


\subsection{Apparatus}

The surface morphologies of the NC material and NC-PEI composite were characterized by scanning electron microscope (Zeiss Sigma 300, Gemini, Jena, Germany) and transmission electron microscope (JEOL JEM-2100, Tokyo, Japan). X-ray diffraction (XRD) patterns were collected with a powder X-ray diffractometer (D8 Advance, Bruker AXS, Karlsruhe, Germany) with $\mathrm{Cu} \mathrm{K} \alpha$ radiation $(\lambda=0.154056 \mathrm{~nm})$. X-ray photoelectron spectroscopy (Thermo Electron ESCALAB250 XPS Spectrometer) was used to characterize the NC nanohybrid composition and element state. C1s $(284.8 \mathrm{eV})$ was utilized for calibrating the binding energies of the acquired XPS spectra. Cyclic voltammetry (CV) were evaluated with an electrochemical workstation (CHI 660E, Shanghai Chenhua Instrument Co. Ltd., Shanghai, China) with a scan rate of $0.1 \mathrm{mV} \mathrm{s}^{-1}$ in the potential range of -0.6 to $0.4 \mathrm{~V}$. Second-order derivative linear sweep voltammetry (SDLSV) was collected with a model JP-303E polarographic analyzer (Chengdu Instrument Factory, Chengdu, China) for quantitative analysis. A conventional three-electrode system was used throughout electrochemical measurements, which consists of an unmodified or modified GCE (id = $3.0 \mathrm{~mm}$ ) as the working electrode, a platinum wire as the counter electrode and a saturated calomel electrode (SCE) as the reference electrode. For $\mathrm{pH}$ measurements, the $\mathrm{pH}-3 \mathrm{c}$ Model $\mathrm{pH}$ meter (Shanghai Leichi Instrument Factory, Shanghai, China) with a combined glass electrode was used.

\subsection{Synthesis of NC Material}

Because of the amino and carbonyl groups in formamide molecules, the Schiff's base reaction between the amino groups and carbonyl groups of the formamide molecules took place by solvothermal method to form a one-dimensional $\mathrm{C}=\mathrm{N}$ molecular chain. The preparation of $\mathrm{NC}$ is presented in the following steps: formamide $(30 \mathrm{~mL})$ was added to a $50 \mathrm{~mL}$ Teflon-lined autoclave. After solvothermal self-polymerization reaction at $180{ }^{\circ} \mathrm{C}$ for $12 \mathrm{~h}$, a brown-black product was taken out by high speed centrifugation; washed with ultrapure water and ethanol three times each; and vacuum dried at $60{ }^{\circ} \mathrm{C}$ overnight. The collected product was then placed in a corundum boat with a cover, and the pyrolysis mode of a tubular furnace was set for two-step pyrolysis: In the first step, the temperature was set at $400{ }^{\circ} \mathrm{C}$ for $2 \mathrm{~h}$, and the heating rate was $5^{\circ} \mathrm{C} \mathrm{min}^{-1}$. In the second step, the temperature was set at $900{ }^{\circ} \mathrm{C}$ for $2 \mathrm{~h}$, and the heating rate was $10{ }^{\circ} \mathrm{C} \mathrm{min}{ }^{-1}$. Finally, the brown-black sample carried in a corundum boat was pyrolyzed in a $\mathrm{N}_{2}$ atmosphere, and the N-doped carbon material (denoted as NC) was prepared.

\subsection{Fabrication of NC-PEI/GCE}

Before modifying the glassy carbon electrode (GCE, $3 \mathrm{~mm}$ in diameter), the exposed GCE was polished into a mirror-like shape with $0.05 \mu \mathrm{m}$ alumina powder slurry, washed thoroughly with ultrapure water and ethanol for $1 \mathrm{~min}$ each in turn, and then dried under an infrared lamp. To form a $1.0 \mathrm{mg} \mathrm{mL}^{-1}$ solution, $10.0 \mathrm{mg}$ of PEI were added into $10 \mathrm{~mL}$ water. Then, $1.0 \mathrm{mg}$ NC material was added to $1.0 \mathrm{~mL}$ PEI aqueous solution $\left(1.0 \mathrm{mg} \mathrm{mL}^{-1}\right)$, and the NC material was uniformly dispersed by ultrasonic dispersion for 3 min. Finally, $5.0 \mu \mathrm{L}$ NC-PEI suspension was dropped onto the polished GCE surface and dried under an infrared lamp to prepare the NC-PEI/GCE, which was directly used as the working electrode for the detection of 4-NP. As a comparison, the pure NC (dispersed in water)modified electrode (denoted as NC/GCE) and the PEI film-modified GCE (denoted as PEI/GCE) were prepared by similar process. The fabricated modified electrodes were stored in air when not in use. Scheme 1 gives the preparation process of the NC-PEI/GCE. 

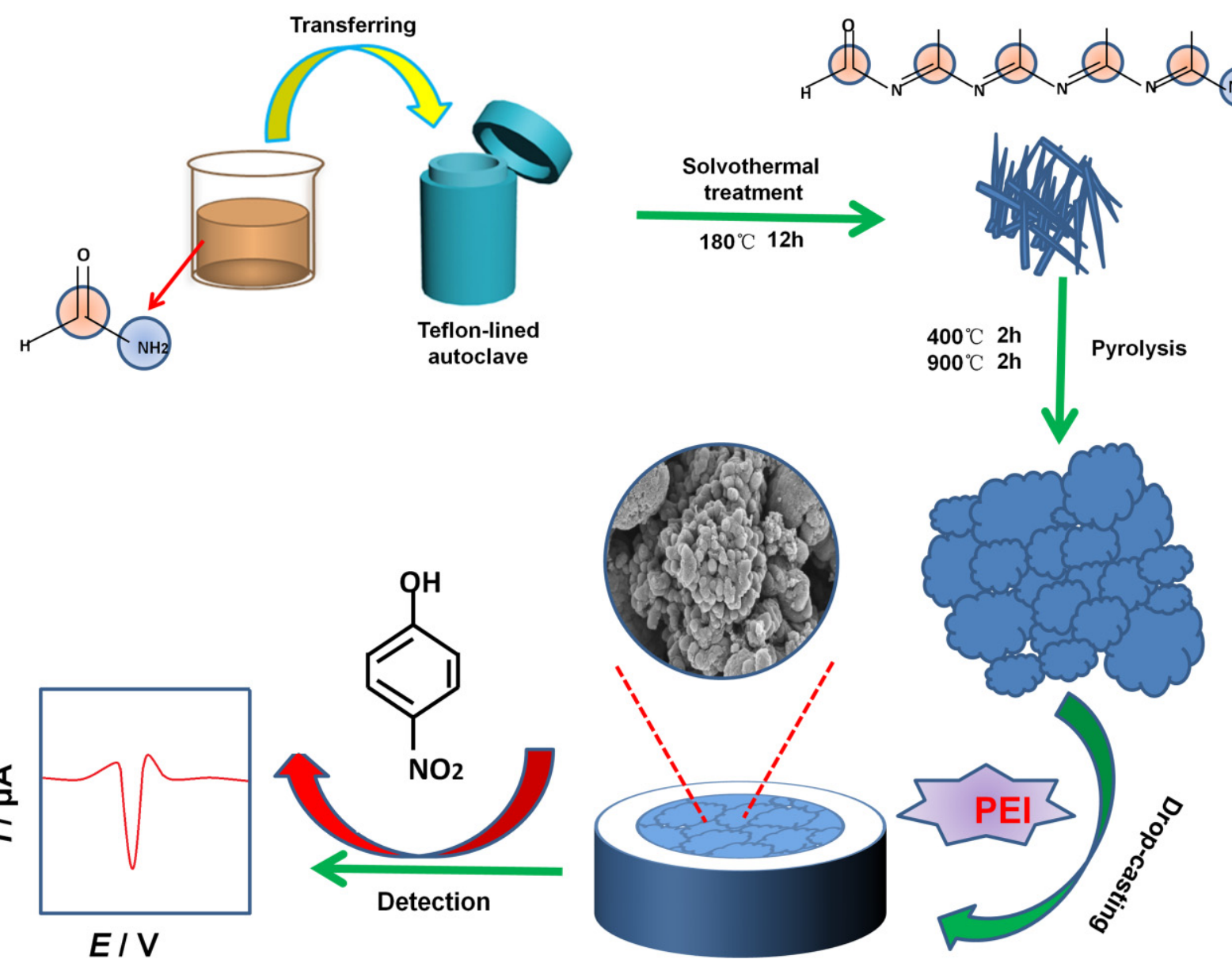

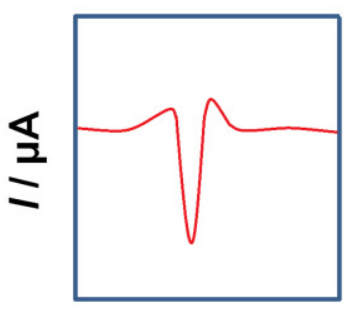

$E I V$

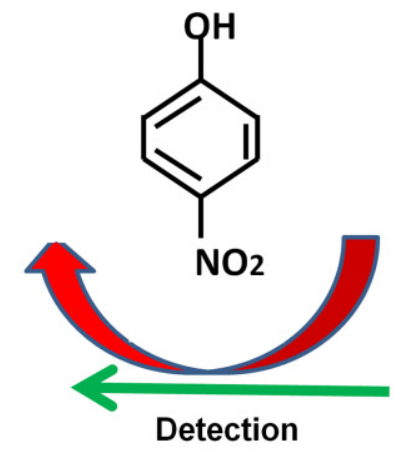

Scheme 1. Synthesis of the NC material and the construction of the NC-PEI/GCE-based electrochemical 4-NP sensor.

\subsection{Procedure}

For voltammetric measurements, firstly, an appropriate volume of 4-NP was added into an electrochemical cell of $10 \mathrm{~mL}$ containing $0.2 \mathrm{M} \mathrm{H}_{2} \mathrm{SO}_{4}$ solution. The three-electrode system was then immersed in the solution. The measurement was carried out after an 150-s accumulation at the potential of $0.2 \mathrm{~V}$. Cyclic voltammetry $(\mathrm{CV})$ was measured with a scan rate of $0.1 \mathrm{~V} \mathrm{~s}^{-1}$ in the potential range of -0.6 to $0.4 \mathrm{~V}$, and second-order derivative linear sweep voltammetry (SDLSV) was measured in the potential range of $0.2 \mathrm{~V}$ to $-0.7 \mathrm{~V}$. After each measurement, the modified electrode was immersed in $0.2 \mathrm{M} \mathrm{H}_{2} \mathrm{SO}_{4}$ solution and scanned several times in the same potential range to obtain a new electrode surface. The same procedure was applied for water sample analysis. All the electrochemical experiments were carried out at room temperature, and oxygen was removed from the test solution by introducing nitrogen before measurement.

\section{Results and Discussion}

\subsection{Characterization of NC and NC-PEI Composite}

The surface morphologies of the NC and NC-PEI composite were studied by scanning electron microscopy (SEM). As shown in Figure 1a, the NC material was nodular, and its surface is very rough, similar to broccoli. Compared with the NC material, the typical morphology of NC-PEI is almost the same. However, Figure $1 \mathrm{~b}$ shows that the dispersion of NC in in PEI solution is greatly improved, which indicates that the addition of the PEI has no effect on the morphology of the material, but only improves the dispersion of the $\mathrm{NC}$ material in water. From the TEM image of NC in Figure 1c, obvious two-dimensional 
folds and overlapping nanosheets can be observed. The crystal structure of the synthesized NC material was analyzed by XRD. It can be seen from Figure $1 \mathrm{~d}$ that the NC material has a peak at $2 \theta=26.6^{\circ}$, which corresponds to the typical peak (002) of the graphite phase of carbon nitride. The XRD result indicated that the NC material has good crystallinity and high purity.
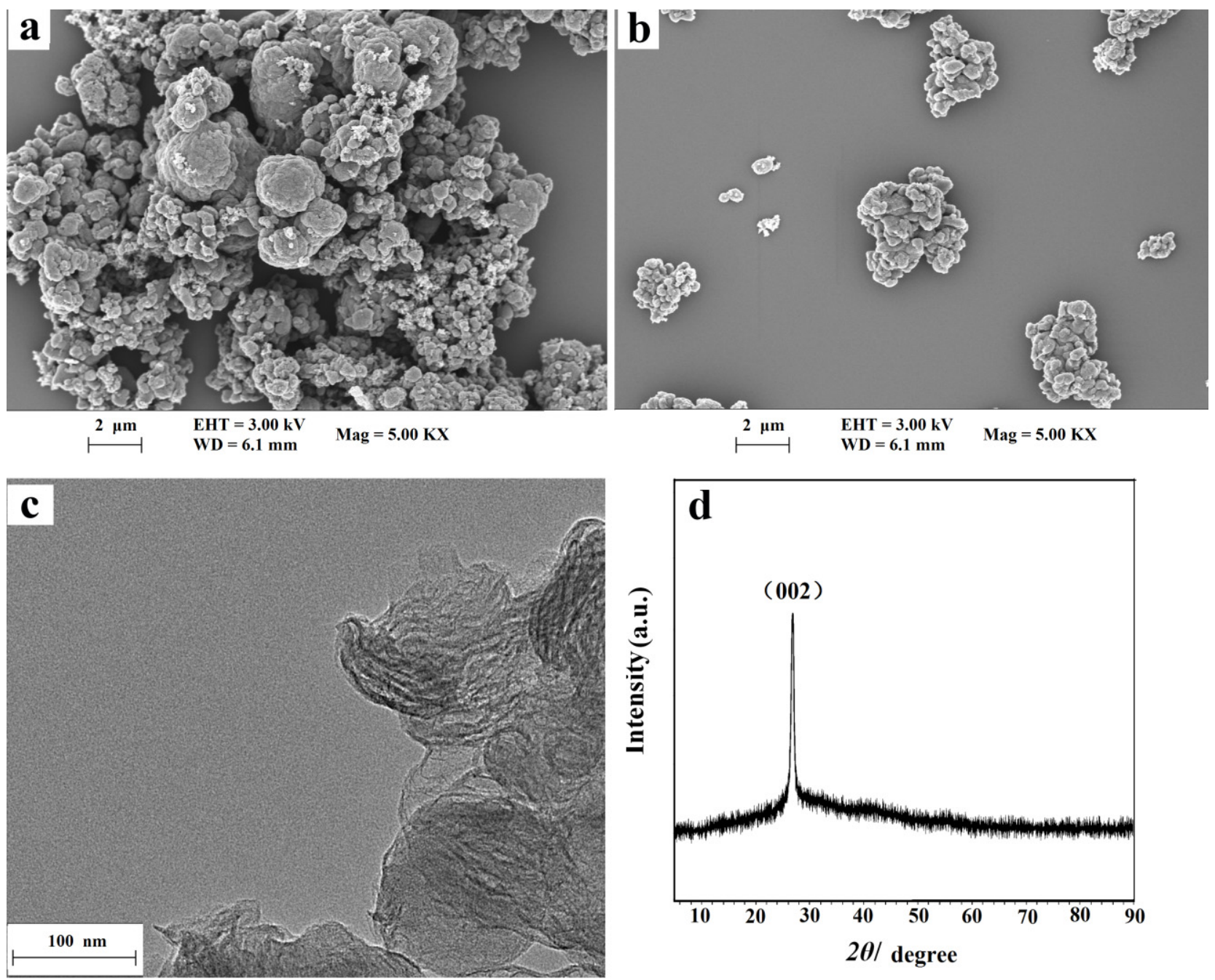

Figure 1. SEM images of NC nanohybrid (a) and NC-PEI composite (b); TEM image of NC nanohybrid (c) and XRD pattern of NC nanohybrid (d).

The elemental composition and chemical state of the material were also investigated by XPS, as shown in Figure $2 \mathrm{a}-\mathrm{c}$. The XPS spectra of the NC nanohybrid (Figure 2a) revealed that the atomic percentages of $\mathrm{C}, \mathrm{O}$ and $\mathrm{N}$ in this sample are $86.79 \%, 4.88 \%$ and $8.33 \%$, respectively. In addition, the three characteristic peaks of $\mathrm{C}-\mathrm{C}(284.6 \mathrm{eV})$, $\mathrm{C}-\mathrm{O} / \mathrm{C}-\mathrm{N}(285.8 \mathrm{eV})$ and $\mathrm{N}-\mathrm{C}=\mathrm{N} / \mathrm{C}=\mathrm{O}(288.9 \mathrm{eV})$ in the high-resolution $\mathrm{C} 1 \mathrm{~s}$ spectrum (Figure $2 \mathrm{~b}$ ) confirmed that the $\mathrm{N}$ element has been successfully doped into the carbon material [44]. Four characteristic peaks of pyridine N (398.1 eV), pyrrole N (399.4 eV), graphite $\mathrm{N}(400.8 \mathrm{eV})$ and oxidation state $\mathrm{N}(403.4 \mathrm{eV})$ were found in the high-resolution $\mathrm{N}$ 1 s spectra (Figure 2c). The above XPS results show that the synthesized NC nanohybrid contains nitrogen and carbon elements, which further verifies the effectiveness of the XRD results. Generally, the electrochemical performance of nanocomposites can be improved by doping the $\mathrm{N}$ element in carbon nanomaterials. Therefore, $\mathrm{N}$-doped carbon nanocomposites can effectively improve the performance of modified electrodes $[45,46]$. 

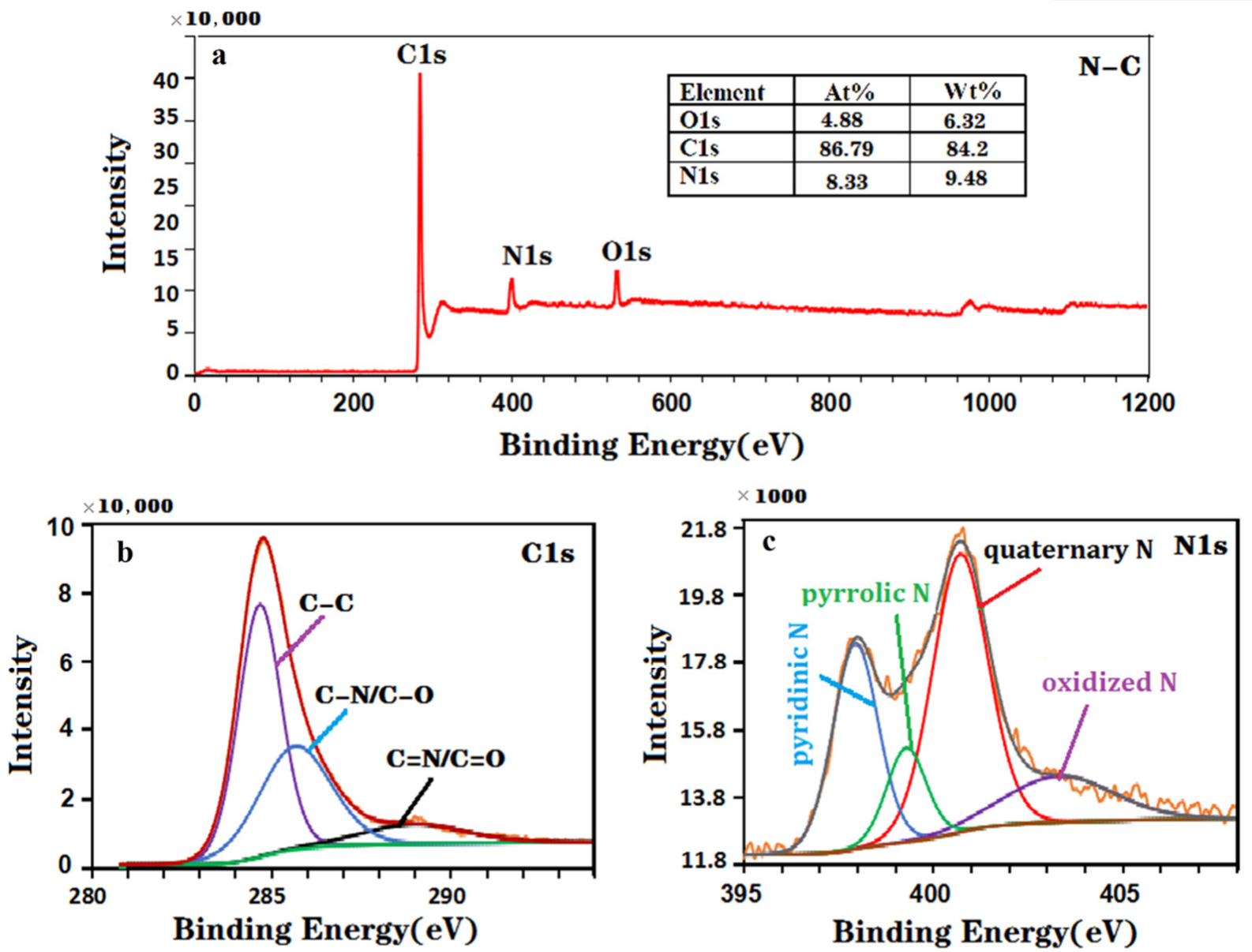

Figure 2. XPS spectra of the NC nanohybrid: (a) survey spectrum, (b) C1s spectrum and (c) N1s spectrum.

\subsection{Electrochemical Characterization of Different Electrodes}

The electrochemical behaviors of different electrodes (bare GCE, PEI/GCE, NC/GCE and NC-PEI/GCE) were investigated using potassium ferricyanide as probe by CV technique. The corresponding cyclic voltammograms (Figure 3) showed that the current of oxidation peak $\left(I_{\mathrm{pa}}\right)$ and reduction peak $\left(I_{\mathrm{pc}}\right)$ of $\mathrm{K}_{3}\left[\mathrm{Fe}(\mathrm{CN})_{6}\right]$ on bare GCE electrodes were $12.53 \mu \mathrm{A}$ and $13.95 \mu \mathrm{A}$, respectively, and the peak-to-peak separation $\left(\Delta E_{\mathrm{p}}\right)$ was $110 \mathrm{mV}$ (curve a). Compared with the bare GCE, the redox peak current of $\mathrm{K}_{3}\left[\mathrm{Fe}(\mathrm{CN})_{6}\right]$ on the $\mathrm{PEI} / \mathrm{GCE}$ was slightly increased $\left(I_{\mathrm{pa}}=16.87 \mu \mathrm{A}, I_{\mathrm{pc}}=17.34 \mu \mathrm{A}\right.$, curve $\left.\mathrm{b}\right)$. This may be due to the good interaction of the polymeric cation in the PEI with $\mathrm{Fe}(\mathrm{CN})_{6}{ }^{3-/ 4-}$ anions. At the $\mathrm{NC} / \mathrm{GCE}$, the electrochemical response of $\mathrm{K}_{3}\left[\mathrm{Fe}(\mathrm{CN})_{6}\right]$ is further enhanced. The peak current is greatly increased $\left(I_{\mathrm{pa}}=22.82 \mu \mathrm{A}, I_{\mathrm{pc}}=22.63 \mu \mathrm{A}\right)$, and the $\Delta E_{\mathrm{p}}$ decreased to $44 \mathrm{mV}$ (curve c). This is mainly because high $\mathrm{N}$ content doping in NC materials changes the structure and charge density of the carbon materials and increases the electron density and electron migration rate on the surface of the carbon materials [47-49]. At the same time, $\mathrm{N}$-doping provides sufficient active centers for catalytic reaction. Compared with the former three electrodes, the largest redox peak currents of $\mathrm{K}_{3}\left[\mathrm{Fe}(\mathrm{CN})_{6}\right]$ were obtained by the NC-PEI/GCE $\left(I_{\mathrm{pa}}=37.58 \mu \mathrm{A}, I_{\mathrm{pc}}=37.27 \mu \mathrm{A}\right)$, which may be closely related to the large specific surface area, good electrical conductivity of the NC composites and the good dispersibility and adsorption capacity of PEI, as well as the synergistic effect between them. According to the Randles-Sevcik equation [50], the effective active areas of different electrodes can be calculated:

$$
I_{p}=\left(2.69 \times 10^{5}\right) n^{3 / 2} D^{1 / 2} A C v^{1 / 2}
$$




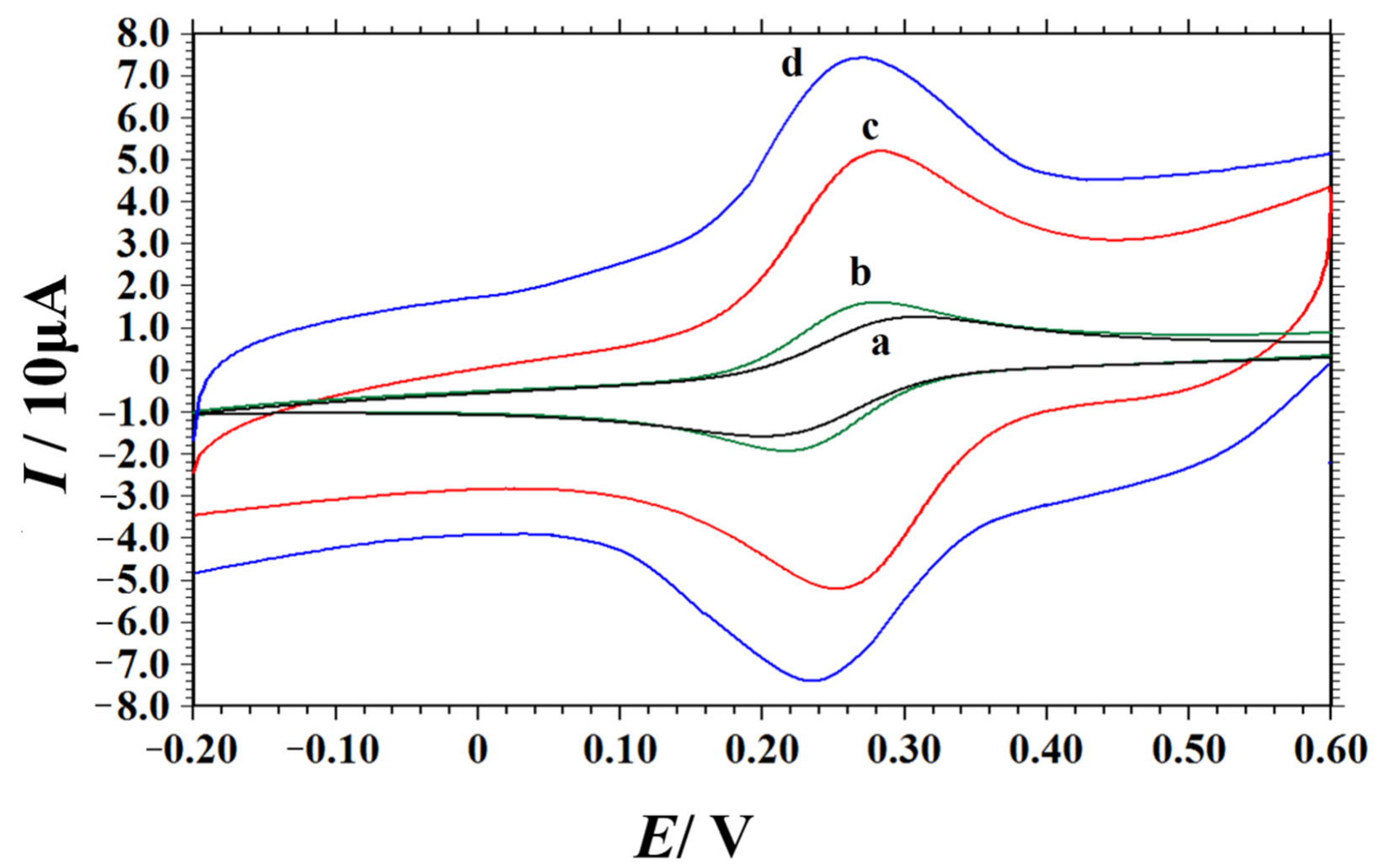

Figure 3. Cyclic voltammograms of $1.0 \mathrm{mM} \mathrm{K}_{3}\left[\mathrm{Fe}(\mathrm{CN})_{6}\right]$ in $0.5 \mathrm{M} \mathrm{KCl}$ solution obtained at bare GCE (a), PEI/GCE (b), NC/GCE (c) and NC-PEI/GCE (d). Scan rate: $0.1 \mathrm{~V} \mathrm{~s}^{-1}$.

In the above formula, $I_{p}$ is the peak current $(\mathrm{A}), n$ is the number of electrons transfer, $D$ is the diffusion coefficient of $\mathrm{K}_{3}\left[\mathrm{Fe}(\mathrm{CN})_{6}\right]\left(D=6.3 \times 10^{-6} \mathrm{~cm}^{2} \mathrm{~s}^{-1}\right)$ [51], $A$ is the electrochemical active area $\left(\mathrm{cm}^{2}\right), C$ is the concentration of $\mathrm{K}_{3}\left[\mathrm{Fe}(\mathrm{CN})_{6}\right]\left(\mathrm{mol} \mathrm{cm}^{-3}\right)$ and $v$ is the scan rate $\left(\mathrm{V} \mathrm{s}^{-1}\right)$. Combined with the slope of the above linear equation, the effective active areas of the bare GCE, PEI/GCE, NC/GCE and NC-PEI/GCE were calculated to be $0.065 \mathrm{~cm}^{2}$, $0.081 \mathrm{~cm}^{2}, 0.106 \mathrm{~cm}^{2}$ and $0.175 \mathrm{~cm}^{2}$, respectively. These results clearly showed that the electrochemical active area of the electrode was effectively increased by the NC-PEI/GCE, which is mainly due to the good dispersion effect of PEI on the NC material.

\subsection{Voltammetric Behavior of 4-NP on Different Electrodes}

Accumulation can improve the amount of 4-NP on the electrode surface, and then obviously improve the determining sensitivity. The cyclic voltammograms of $0.1 \mathrm{mM} 4-\mathrm{NP}$ in $0.2 \mathrm{M} \mathrm{H}_{2} \mathrm{SO}_{4}$ solution obtained at the NC-PEI/GCE without accumulation and with accumulation (90 s) were shown in the insert of Figure $4 \mathrm{~A}$. It was obvious that after accumulation, the CV responses of $0.1 \mathrm{mM} 4-\mathrm{NP}$ increased dramatically. In order to demonstrate the unique and excellent performance of NC-PEI/GCE in the determination of 4-NP, the CV curves of $0.1 \mathrm{mM} 4-\mathrm{NP}$ on the bare GCE, PEI/GCE, NC/GCE and NC-PEI/GCE were compared after accumulating at $0.2 \mathrm{~V}$ for $90 \mathrm{~s}$. According to the currently accepted mechanism for the electroreduction in aromatic and heteroaromatic nitro compounds [52-54], the reduction peak is attributed to the reduction of p-nitrophenol to the corresponding p-(hydroxyamino)phenol. As shown in Figure 4A, on the bare GCE (curve a), an inconspicuous reduction peak appeared at the potential of $-0.493 \mathrm{~V}$, indicating a slow electron transfer kinetic. The peak current increased slightly on the PEI/GCE under the same conditions (curve (b)), indicating that the reduction of 4-NP on the PEI/GCE is more favorable, which may be due to the hydrogen bonding interactions between the amino group of PEI and the hydroxyl group of 4-NP. The curves (c) and (d) confirmed the catalytic performance of the NC/GCE and NC-PEI/GCE for 4-NP reduction. Under the same conditions, the reduction 
peak current of 4-NP on the NC/GCE $(85.98 \mu \mathrm{A})$ was significantly greater than that on the bare GCE or on PEI/GCE, and the peak potential also shifted positively $(-0.327 \mathrm{~V})$ (curve (c)). This may be attributed to the unique characteristics of NC such as a higher charge density on the surface of materials as well as good electrical conductivity because of the large specific surface area and higher N content of NC materials [47-49]. When the NC-PEI/GCE was used, a maximum sharp 4-NP reduction peak (117.4 $\mu \mathrm{A})$ appeared at $-0.270 \mathrm{~V}$, which indicates that NC and PEI have synergistic enhancement effect on 4-NP. The highest peak current and the lowest reduction overpotential are the evidence that the NC-PEI composite has good electrocatalytic performance for 4-NP. Due to the excellent properties of NC and PEI, the accumulation efficiency of 4-NP on the electrode surface is greatly improved, and the electron transfer rate on the electrode surface is accelerated, which is beneficial to the sensitive detection of 4-NP on the NC-PEI/GCE.
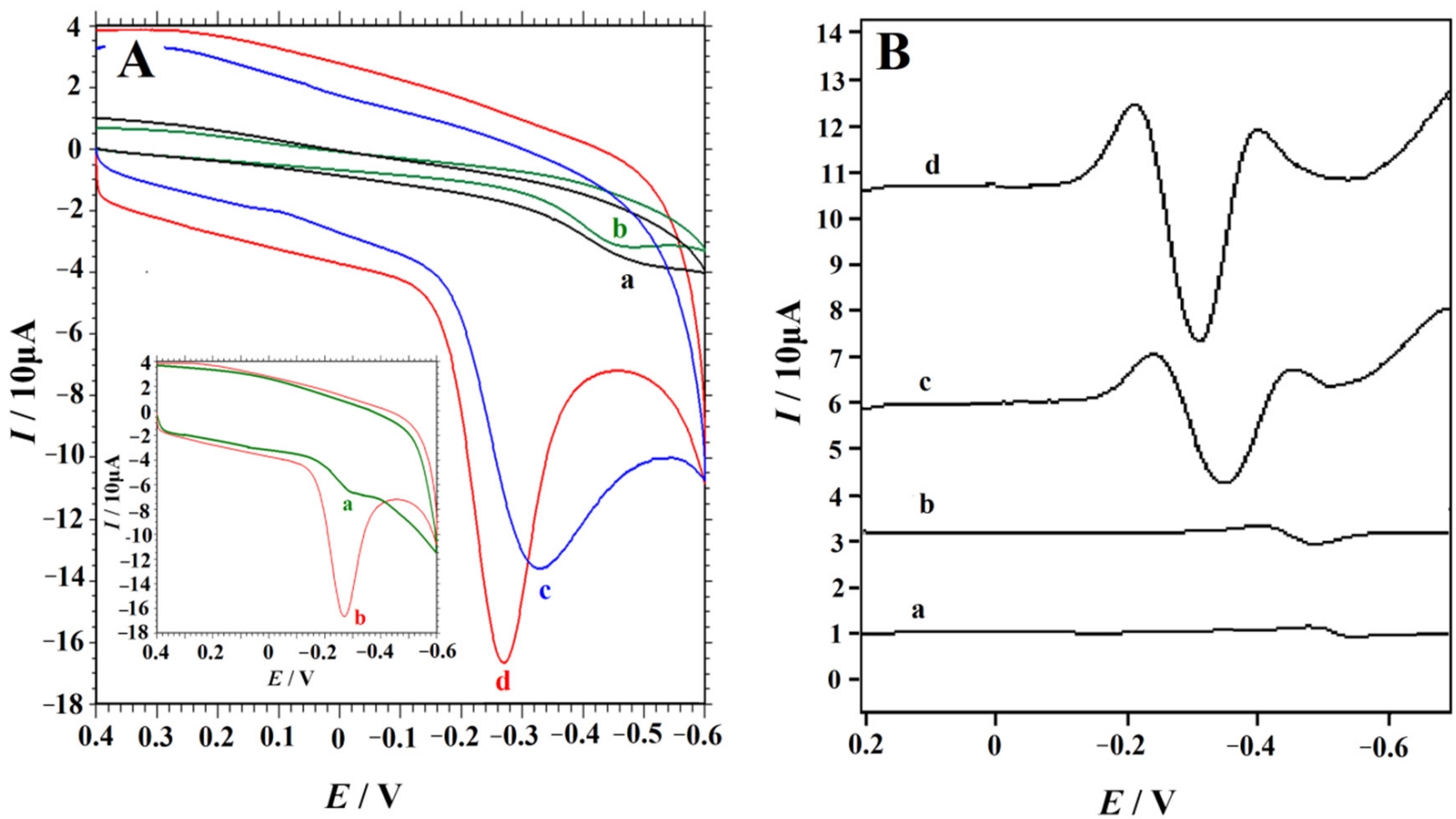

Figure 4. Cyclic voltammograms (A) and second-derivative linear sweep voltammograms (B) of $0.1 \mathrm{mM}$ 4-NP in $0.2 \mathrm{M} \mathrm{H}_{2} \mathrm{SO}_{4}$ solution obtained at bare GCE (curve a), PEI/GCE (curve b), NC/GCE (curve c) and NC-PEI/GCE (curve d) after accumulating at $0.2 \mathrm{~V}$ for $90 \mathrm{~s}$, scan rate: $0.1 \mathrm{~V} \mathrm{~s}^{-1}$. Inset of a: $\mathrm{CV}$ curves of $0.1 \mathrm{mM} 4-\mathrm{NP}$ in $0.2 \mathrm{M} \mathrm{H}_{2} \mathrm{SO}_{4}$ solution without accumulation (a) and after accumulation for $90 \mathrm{~s}$ (b).

To further illustrate the performance of different electrodes on 4-NP detection, the SDLSV response of different electrodes to $0.1 \mathrm{mM} 4-\mathrm{NP}$ in $0.2 \mathrm{M} \mathrm{H}_{2} \mathrm{SO}_{4}$ solution under the same conditions was collected (Figure 4B). As an electrochemical technique with high signalto-noise ratio and high sensitivity, SDLSV is widely used in quantitative analysis [55-57]. The voltammograms of $0.1 \mathrm{mM} 4-\mathrm{NP}$ obtained at the bare GCE, PEI/GCE, NC/GCE and NC-PEI/GCE were compared. The results showed that NC-PEI composites have the best effect on 4-NP reduction. The 4-NP reduction peak current on the NC-PEI/GCE is about two-fold higher than that on the NC/GCE. Meanwhile, it was 22-fold and 13-fold higher than that on the bare GCE and PEI/GCE. These phenomena confirm that NC-PEI composites can improve the electrocatalytic reduction rate of 4-NP, which can be attributed to the combined advantages of the composites, including the good catalytic activity of NC materials with 4-NP and the hydrogen bonding interaction of PEI with the NC materials and 4-NP, which could facilitate the improvement of the electron transfer rate and the accumulation efficiency of 4-NP. 


\subsection{Optimization of the Determination Conditions}

In order to maximize the electrochemical signal of 4-NP on the NC-PEI/GCE surface, various analytical parameters were optimized. To obtain the best supporting electrolyte for 4-NP detection, $\mathrm{HCl}, \mathrm{H}_{2} \mathrm{SO}_{4}, \mathrm{HNO}_{3}, \mathrm{H}_{3} \mathrm{PO}_{4}, \mathrm{HAc}-\mathrm{NaAc}(\mathrm{pH} 4-6), \mathrm{HAc}-\mathrm{NH}_{4} \mathrm{Ac}(\mathrm{pH}$ 4-6), phosphate buffer ( $\mathrm{pH}$ 3-9) and Britton-Robinson (B-R) buffer ( $\mathrm{pH}$ 3-9) (each $0.1 \mathrm{M}$ ) were selected as the supporting electrolytes for the test. The above supporting electrolytes were added to the solution containing $0.1 \mathrm{mM} 4-\mathrm{NP}$, respectively, and the SDLSV curves were compared. The results show that the peak shape of 4-NP is the best, and the peak current is the largest in the $\mathrm{H}_{2} \mathrm{SO}_{4}$ solution. In addition, the acidity of the solution also has a significant effect on the electrochemical response of 4-NP. Since the determination is carried out in a $\mathrm{H}_{2} \mathrm{SO}_{4}$ solution, the $\mathrm{pH}$ value of the solution can be changed by changing the concentration of $\mathrm{H}_{2} \mathrm{SO}_{4}$. The electrochemical response of 4-NP at different concentrations of $0.02-0.5 \mathrm{M}$ was tested (Figure $5 \mathrm{~A}$ ), and the results showed that in the concentration range of $0.2-0.5 \mathrm{M}$, the reduction current of 4-NP reached the maximum and was basically unchanged (Figure 5B). Therefore, we chose the concentration of $0.2 \mathrm{M}$ in the following studies. In addition, Figure $5 \mathrm{C}$ shows that with $\mathrm{pH}$ increases from 0 to 1.5 , the value of the 4 -NP reduction peak potential $\left(E_{\mathrm{p}}\right)$ decreases linearly, indicating that there was a proton transfer in the 4-NP reduction reaction, and the corresponding equation is as follows:

$$
E_{\mathrm{pa}}(\mathrm{V})=-0.05849 p H-0.2676\left(\mathrm{R}^{2}=0.9980\right)
$$
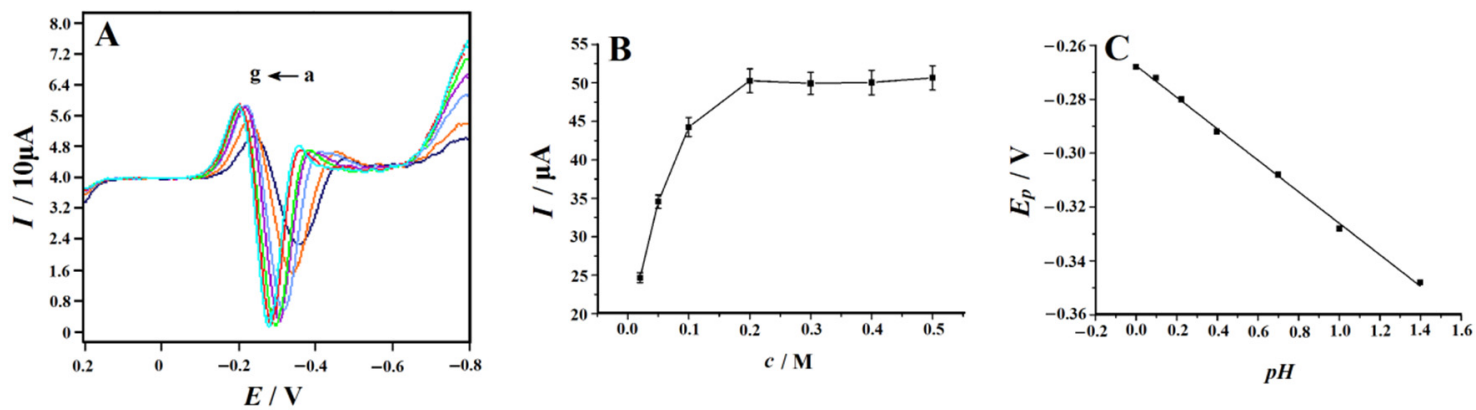

Figure 5. (A) Second-derivative linear sweep voltammograms of $0.1 \mathrm{mM} 4$-NP recorded on the $\mathrm{NC}-\mathrm{PEI} / \mathrm{GCE}$ at a scan rate of $0.1 \mathrm{~V} \mathrm{~s}^{-1}$ in $\mathrm{H}_{2} \mathrm{SO}_{4}$ solution with different concentrations (from a to $g$ are $0.02,0.05,0.1,0.2,0.3,0.4$ and $0.5 \mathrm{M}$ ) after accumulating at $0.2 \mathrm{~V}$ for $150 \mathrm{~s}$; (B) plot of the peak current versus $\mathrm{H}_{2} \mathrm{SO}_{4}$ concentration, error bars represent $\mathrm{SD}, n=3$; (C) the linear relationship between the peak potential and $\mathrm{pH}$.

The slope of $58.49 \mathrm{mV}$ is equal to the Nernst slope, indicating that the ratio of the number of electrons transferred to the number of reacting protons is equal to 1 .

We set different accumulation potential values in the range of $-0.1 \mathrm{~V}$ to $0.5 \mathrm{~V}$ and studied the effect of accumulation potential on the electrochemical reduction behavior of 4-NP (accumulation time of $150 \mathrm{~s}$ ). Figure $6 \mathrm{a}$ is the relationship diagram of the experimental data obtained: when the accumulation potential is $0.2 \mathrm{~V}$, the reduction response peak of 4-NP on the NC-PEI/GCE sensor is the largest. Therefore, $0.2 \mathrm{~V}$ was selected as the best accumulation potential. In addition, the effect of accumulation time on the voltammetric behavior of $0.1 \mathrm{mM} 4-\mathrm{NP}$ on the NC-PEI/GCE surface was also studied (the accumulation potential was set at $0.2 \mathrm{~V}$ ). Figure $6 \mathrm{~b}$ shows a graph of the signal of the peak current relative to the accumulation time, indicating when the accumulation time is less than $150 \mathrm{~s}$, the 4-NP reduction peak current is proportional to the accumulation time. After $150 \mathrm{~s}$ accumulation, the current was stable, and the equilibrium was reached. Therefore, the accumulation time was set to $150 \mathrm{~s}$ to obtain a better sensitivity for 4-NP detection. 

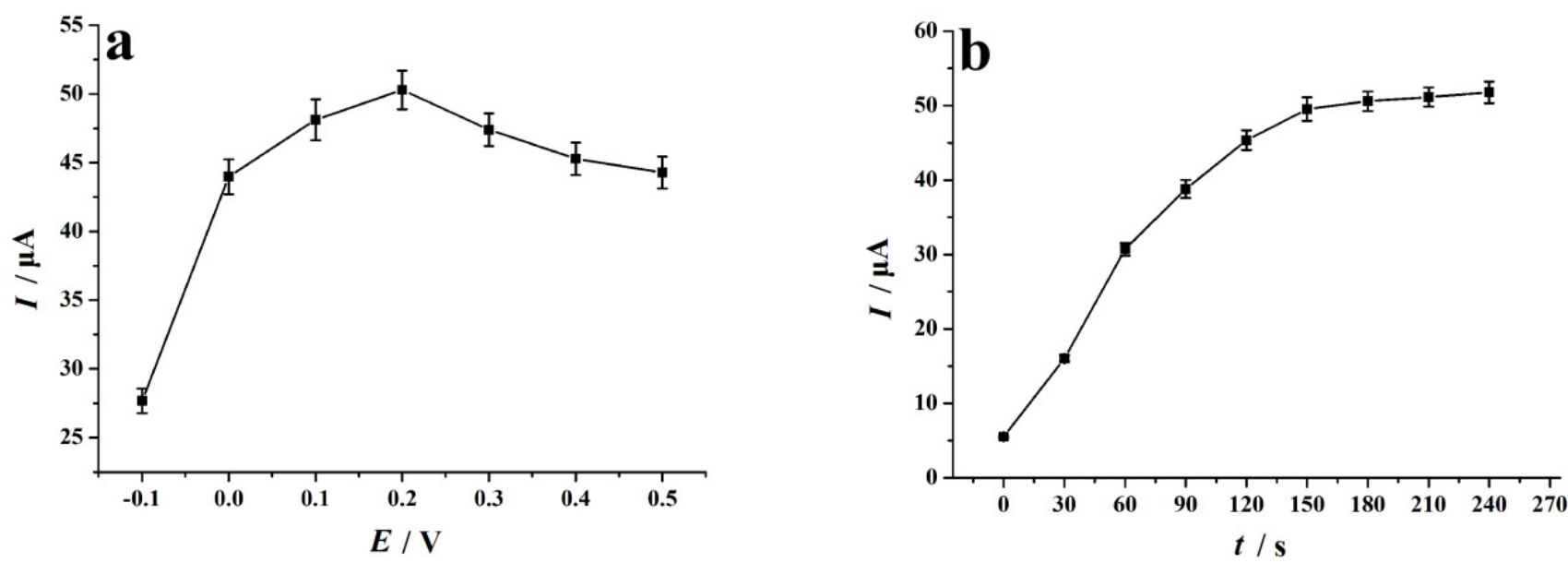

Figure 6. (a) Effect of accumulation potential on the peak current of $0.1 \mathrm{mM} 4-\mathrm{NP}$ after $150 \mathrm{~s}$ accumulation time; (b) effect of accumulation time on the peak current of $0.1 \mathrm{mM} 4-\mathrm{NP}$ at the accumulation potential of $0.2 \mathrm{~V}$. Supporting electrolyte: $0.2 \mathrm{M} \mathrm{H}_{2} \mathrm{SO}_{4}$ solution, scan rate: $0.1 \mathrm{~V} \mathrm{~s}^{-1}$, error bars represent $\mathrm{SD}, n=3$.

\subsection{Effect of Scan Rate}

In order to study the kinetic process of an electrode reaction of 4-NP on the NCPEI/GCE, the effect of the scan rate on the electrochemical behavior of 4-NP on the modified electrode was investigated by a $\mathrm{CV}$ technique. The cyclic voltammograms of $0.1 \mathrm{mM} 4-\mathrm{NP}$ in $0.2 \mathrm{M} \mathrm{H}_{2} \mathrm{SO}_{4}$ solution in the range of 30 to $300 \mathrm{mV} \mathrm{s}^{-1}$ were shown in Figure 7A. As shown in Figure 7B. when the square root of the sweep speed $\left(v^{1 / 2}\right)$ value increases, the current intensity value increases linearly, and this equation was expressed as: $I_{\mathrm{p}}(\mu \mathrm{A})=64.299 v^{1 / 2}-6.9566\left(\mathrm{R}^{2}=0.995\right)$. The result indicates that the diffusion-controlled electrode process of 4-NP occurs on the surface of NC-PEI/GCE in the studied range of the scan rate.
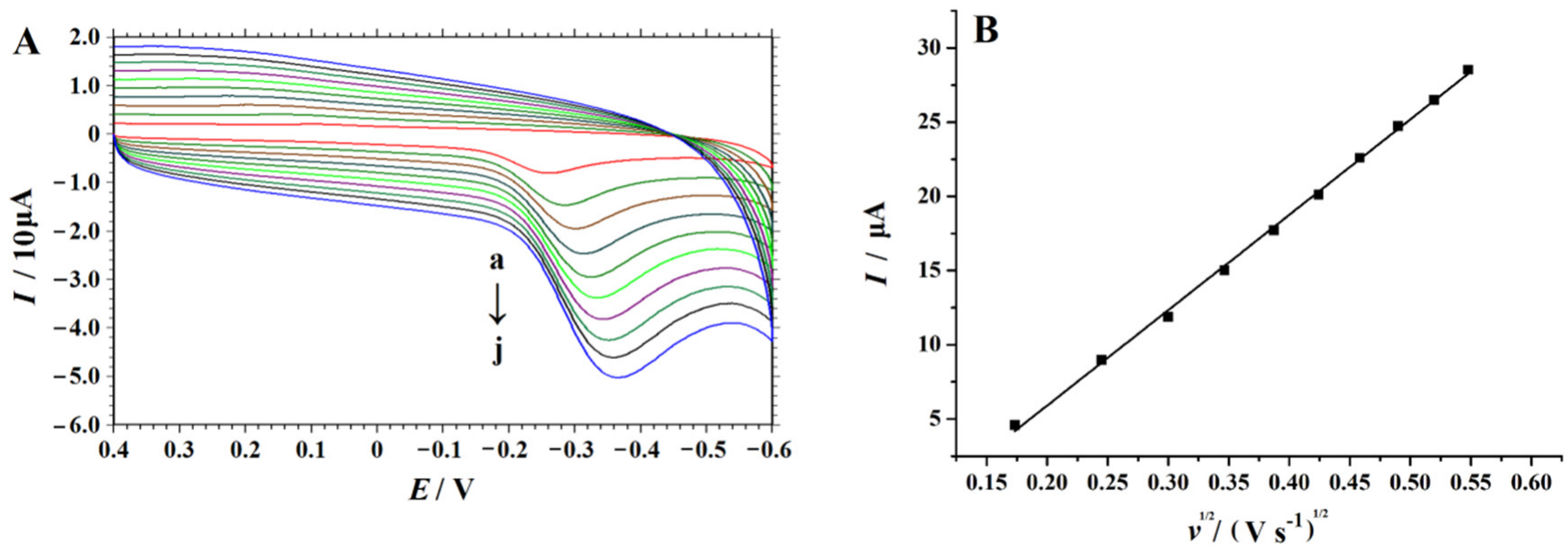

Figure 7. (A) Cyclic voltammograms obtained on the NC-PEI/GCE in $0.2 \mathrm{M} \mathrm{H}_{2} \mathrm{SO}_{4}$ solution containing $0.1 \mathrm{mM}$ 4-NP under different scan rates (from a to $\mathrm{j}$ are $0.03,0.06,0.09,0.12,0.15,0.18,0.21,0.24,0.27$ and $0.3 \mathrm{~V} \mathrm{~s}^{-1}$ ) after accumulating at $0.2 \mathrm{~V}$ for $30 \mathrm{~s}$, (B) Linear relationship fitting between $I_{\mathrm{p}}$ and $v^{1 / 2}$.

\subsection{Determination of 4-NP Using SDLSV}

In order to obtain the linear range and detection limit of the NC-PEI/GCE in the measurement of 4-NP, an SDLSV technique was used to determine 4-NP at different concentrations in $0.2 \mathrm{M} \mathrm{H}_{2} \mathrm{SO}_{4}$ solution. The corresponding voltammograms were shown in Figure $8 \mathrm{~A}, \mathrm{~B}$. The peak current increased with the increase in concentration. Alternatively, as 
shown in Figure 8C,D, when the concentration of 4-NP increased in the range of $0.06-10 \mu \mathrm{M}$ and $10-100 \mu \mathrm{M}$, the response of the sensor was linearly proportional to the concentration of 4-NP. The linear regression equations were: $I_{\mathrm{p}}(\mu \mathrm{A})=1.0716 c(\mu \mathrm{M})+0.1008\left(\mathrm{R}^{2}=0.9985\right)$ and $I_{\mathrm{p}}(\mu \mathrm{A})=0.4425 c(\mu \mathrm{M})+6.3121\left(\mathrm{R}^{2}=0.9963\right)$, respectively. The limit of detection (LOD) was estimated to be $0.01 \mu \mathrm{M}(\mathrm{S} / \mathrm{N}=3)$. Table 1 shows a comparison of the linear ranges and detection limits between some reported electrochemical sensors and NC-PEI/GCE in 4-NP detection. We can clearly recognize that the LOD obtained at the NC-PEI/GCE is lower than that of most reported modified electrodes, but not as good as that of RGO-MIP/GCE [22] and GR/ABPE [27]. However, the outstanding advantages of the NC-PEI/GCE are simple preparation, low price and fast response.
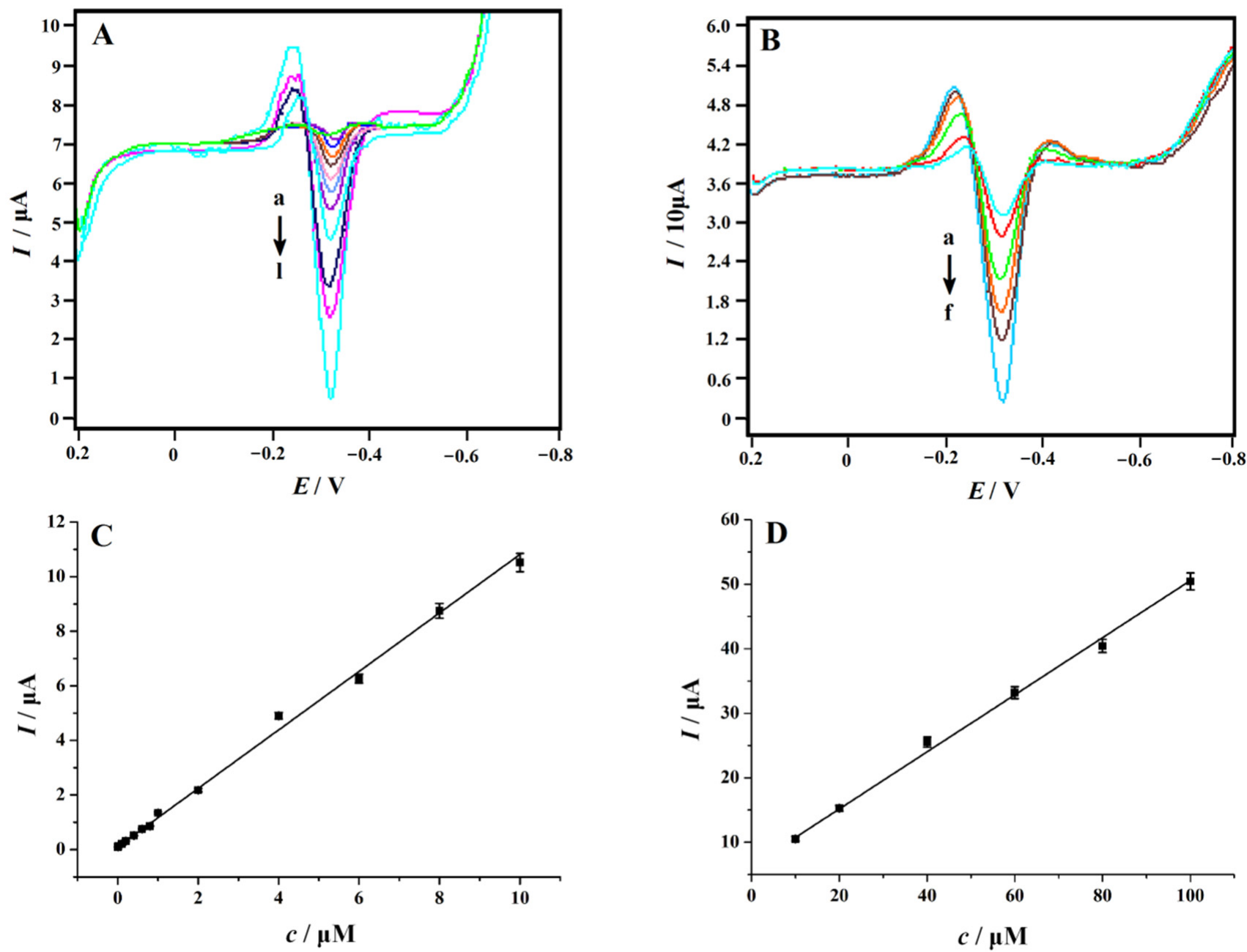

Figure 8. Second-order derivative linear sweep voltammograms of different concentrations of 4-NP recorded on the NC-PEI/GCE after accumulating at $0.2 \mathrm{~V}$ for $150 \mathrm{~s}$. (A) Form a to 1: 0.06, 0.08, 0.1, 0.2, 0.4, 0.6, 0.8, 1.0, 2.0, 4.0, 6.0, 8.0 and $10 \mu \mathrm{M} 4$-NP; (B) Form a to f: 10, 20, 40, 60, 80 and $100 \mu \mathrm{M} 4-\mathrm{NP}$; (C) plots of the peak currents versus 4-NP concentrations in the range of $0.06-10 \mu \mathrm{M}$; and (D) plots of the peak currents versus 4-NP concentrations in the range of 10-100 $\mu \mathrm{M}$, error bars represent SD, $n=3$. 
Table 1. Performance comparison of the NC-PEI/GCE for 4-NP detection with other electrochemical sensors.

\begin{tabular}{ccccc}
\hline Technique & Sensor & $\begin{array}{c}\text { Linear Range } \\
(\boldsymbol{\mu M})\end{array}$ & $\begin{array}{c}\text { Detection } \\
\text { Limit }(\boldsymbol{\mu M})\end{array}$ & Reference \\
\hline${ }^{\mathrm{a}}$ DPV & e PNPI-PANI-PVSA/ITO & Not reported & 1.0 & {$[3]$} \\
DPV & $\mathrm{f}$ CDSBA/CPE & $0.2-1.6$ & 0.01 & {$[20]$} \\
b LSV & $\mathrm{g}$ GO/GCE & $0.1-120$ & 0.02 & {$[21]$} \\
DPV & $\mathrm{h}$ RGO-MIP/GCE & $0.01-100$ & 0.005 & {$[22]$} \\
c SWV & $\mathrm{i}$ PAZ/Pt & $30-90$ & 8.23 & {$[23]$} \\
DPV & $\mathrm{j}$ PTTB/GCE & $0.3-15$ & 0.05 & {$[24]$} \\
$\mathrm{d}$ SDLSV & $\mathrm{k}$ Gr-Chit/ABPE & $0.1-80$ & 0.08 & {$[25]$} \\
SDLSV & 1 S-CHIT/ABPE & $0.08-2$ & 0.03 & {$[26]$} \\
SDLSV & $\mathrm{m}$ GR/ABPE & $0.02-100$ & 0.008 & {$[27]$} \\
SDLSV & $\mathrm{NC}-\mathrm{PEI} / \mathrm{GCE}$ & $0.06-10 ; 10-100$ & 0.01 & This work \\
\hline
\end{tabular}

Note: ${ }^{a}$ differential pulse voltammetry; ${ }^{b}$ linear sweep voltammetry; ${ }^{\mathrm{c}}$ square wave voltammetry; ${ }^{\mathrm{d}}$ second-order linear scan voltammetry; ${ }^{\mathrm{e}}$ molecularly imprinted 4-nitrophenol sensor based on polyaniline-polyvinyl sulfonic acid composite film-modified indium tin oxide glass substrate; ${ }^{\mathrm{f}} \beta$-cyclodextrin functionalized mesoporous silica-modified carbon paste electrode; ${ }^{g}$ graphene oxide film-coated glassy carbon electrode; ${ }^{\text {h }}$ graphene oxide and molecularly imprinted polymer-modified glassy carbon electrode; ${ }^{i}$ polyazulene-modified platinum electrode; $\mathrm{j}$ thiophene-based microporous polymer film-modified glassy carbon electrode ${ }^{\mathrm{k}}$ graphene-chitosan compositemodified acetylene black paste electrode; ${ }^{1}$ alicylaldehyde-modified chitosan-modified acetylene black paste electrode; ${ }^{m}$ acetylene black paste and graphene hybrid electrode.

\subsection{Investigation of the Selectivity}

Some inorganic ions or organic substances were added to the $10 \mu \mathrm{M} 4$-NP solution as interfering substances to study the selectivity of NC-PEI/GCE. The tolerance level was considered to be the ratio of the interfering species concentration per 4-NP, resulting in a relative error of less than or equal to $\pm 5.0 \%$. The experimental results showed that 1000 -fold concentrations of $\mathrm{Na}^{+}, \mathrm{K}^{+}, \mathrm{Cu}^{2+}, \mathrm{Ca}^{2+}, \mathrm{Mg}^{2+}, \mathrm{Pb}^{2+}, \mathrm{Cd}^{2+}, \mathrm{Al}^{3+}, \mathrm{Cr}^{3+} \mathrm{Mn}^{2+}, \mathrm{Cl}^{-}$and $\mathrm{NO}_{3}{ }^{-}$; a 100-fold concentration of phenol, hydroquinone and catechol; a 50-fold concentration of 2-aminophenol, 4-aminophenol, 2-chlorophenol and a two-fold concentration of 2nitrophenol (2-NP) have no interference in the detection of $10 \mu \mathrm{M} 4-\mathrm{NP}$, showing that the NC-PEI/GCE exhibits high selectivity in the detection of 4-NP.

\subsection{Evaluation of the Repeatability, Reproducibility and Stability}

The repeatability, reproducibility and stability of the NC-PEI/GCE were also investigated by SDLSV. Firstly, the voltammograms of $10 \mu \mathrm{M}$ 4-NP in the $0.2 \mathrm{M} \mathrm{H}_{2} \mathrm{SO}_{4}$ solution were recorded for the same NC-PEI/GCE. The relative standard deviation (RSD) of the signals obtained for six repeated measurements was $2.7 \%$, which indicated that the sensor had high repeatability in the determination of 4-NP. In addition, the reproducibility of the sensor was studied to evaluate the reliability of the electrode preparation method. Six different NC-PEI/GCEs were prepared by the same procedure, and the RSD was $3.4 \%$ for the detection of $10.0 \mu \mathrm{M}$ 4-NP. NC-PEI/GCE also showed good stability without changes to the peak current after 200 cyclic voltammetric sweeps in the potential range between 0.2 and $-0.6 \mathrm{~V}$ at the scan rate of $0.1 \mathrm{~V} \mathrm{~s}^{-1}$. The stability of the sensor was also evaluated by recording a signal of $10 \mu \mathrm{M} 4-\mathrm{NP}$ for the same NC-PEI/GCE every day. The results show that the modified electrode maintains about $93.2 \%$ of its initial current response after a week and maintains about $85.1 \%$ of its initial current response after a month. In conclusion, the NC-PEI/GCE has good analytical performance in repeatability, reproducibility and stability and can be used for the determination of 4-NP in real samples.

\subsection{Analysis of the Real Sample}

The suitability of NC-PEI/GCE for the 4-NP determination in water samples was studied. The water samples were determined without any pretreatment. For the analysis of the 4-NP content in real samples, an SDLSV technique and standard addition method were used. The results were shown in Table 2. No electrochemical response of 4-NP 
was found in any of the samples, which may be due to the absence of 4-NP in the water samples, or the concentration of 4-NP was lower than the detection limit of the method. A certain concentration of 4-NP was added, and the signal of SDLSV was recorded. The average value of four parallel measurements was adopted as the determination result. As shown in Table 2 through the spiked concentration of 4-NP in the water sample, the estimated recoveries obtained were between $96.0 \%$ and $104.7 \%$. Therefore, this strategy can be successfully applied to the measurement of 4-NP in real samples.

Table 2. Determination of 4-NP in water samples.

\begin{tabular}{|c|c|c|c|c|}
\hline Samples ${ }^{a}$ & $\begin{array}{c}\text { Added } \\
(\mu \mathrm{M})\end{array}$ & $\begin{array}{l}\text { Found } b \\
(\mu \mathrm{M})\end{array}$ & RSD & $\begin{array}{c}\text { Recovery } \\
(\%)\end{array}$ \\
\hline River water & 5.0 & 5.13 & 3.1 & 102.6 \\
\hline Lake water & 10.0 & 10.38 & 2.8 & 103.8 \\
\hline $\begin{array}{l}\text { Domestic } \\
\text { sewage }\end{array}$ & 40.0 & 38.86 & 3.7 & 97.2 \\
\hline $\begin{array}{l}\text { Industrial waste } \\
\text { water }\end{array}$ & 20.0 & 20.94 & 4.6 & 104.7 \\
\hline Tap water & 1.0 & 0.96 & 2.1 & 96.0 \\
\hline
\end{tabular}

${ }^{a}$ All water samples were collected from Hengyang, China. ${ }^{b}$ Average value of four measurements.

\section{Conclusions}

In this study, a new $\mathrm{C}=\mathrm{N}$ one-dimensional molecular chain can be established by reacting formamides with each other. Then, a novel N-doped carbon material (NC) with high nitrogen content was prepared by a step-by-step carbonization of the Schiff base. The electrochemical sensor base on NC-polyethyleneimine (PEI) composite shows excellent electrocatalytic activity to the 4-NP reduction on the electrode surface due to the excellent electronic, physical and chemical properties of the NC material, as well as the excellent dispersion, adsorption and binding properties of PEI. The diffusion-controlled electrode process of 4-NP occurs on the surface of NC-PEI/GCE, and the determination conditions were optimized. A wide linear range $(0.06 \mu \mathrm{M}$ to $100 \mu \mathrm{M})$ and a low detection limit $(0.01 \mu \mathrm{M})$ were obtained for NC-PEI/GCE. Various environmental water samples were used to check the applicability of the NC-PEI/GCE. In addition, the sensors exhibit good repeatability, reproducibility and stability for 4-NP detection. Therefore, this simple strategy based on NC-PEI nanocomposite has potential application prospects in the design of other electrochemical sensors.

Author Contributions: P.D. and Y.T. conceived and designed the experiments; X.N. performed the experiments; X.N. analyzed the data; H.W. contributed reagents/materials/analysis tools; and X.N. wrote the paper. All authors have read and agreed to the published version of the manuscript.

Funding: Thanks are given for the financial support from the Scientific Research Projects of the Education Department of Hunan Province (no. 20C0289), the Opening Projects of the Key Laboratory of Functional Organometallic Materials, University of Hunan Province (no. GN20K04), and The Doctor Scientific Research Project of Hengyang Normal University(no.2021QD06).

Institutional Review Board Statement: Not applicable.

Informed Consent Statement: Not applicable.

Data Availability Statement: Not applicable.

Conflicts of Interest: The authors declare no conflict of interest. 


\section{References}

1. Nie, X.; Deng, P.; Wang, H.; Tang, Y. Toxic Substance Control Act; US Environmental Protection Agency: Washington, DC, USA, 1979.

2. Nistor, C.; Oubiña, A.; Marco, M.P.; Barceló, D.; Emnéus, J. Competitive flow immunoassay with fluorescence detection for determination of 4-nitrophenol. Anal. Chim. Acta 2001, 426, 185-195. [CrossRef]

3. Roy, A.C.; Nisha, V.S.; Dhand, C.; Ali, M.A.; Malhotra, B.D. Molecularly imprinted polyaniline-polyvinyl sulphonic acid composite based sensor for para-nitrophenol detection. Anal. Chim. Acta 2013, 777, 63-71. [CrossRef]

4. Delnavaz, E.; Amjadi, M. An ultrasensitive chemiluminescence assay for 4-nitrophenol by using luminol-NaIO $\mathrm{N}_{4}$ reaction catalyzed by copper, nitrogen co-doped carbon dots. Spectrochim. Acta A 2020, 241, 118608. [CrossRef]

5. Yang, J.M.; Hu, X.W.; Liu, Y.X.; Zhang, W. Fabrication of a carbon quantum dots-immobilized zirconium-based metal-organic framework composite fluorescence sensor for highly sensitive detection of 4-nitrophenol. Micropor. Mesopor. Mat. 2019, 274, 149-154. [CrossRef]

6. Almási, A.; Fischer, E.; Perjési, P. A simple and rapid ion-pair HPLC method for simultaneous quantitation of 4-nitrophenol and its glucuronide and sulfate conjugates. J. Biochem. Biophys. Methods 2006, 69, 43-50. [CrossRef]

7. Guo, X.; Wang, Z.; Zhou, S. The separation and determination of nitrophenol isomers by high-performance capillary zone electrophoresis. Talanta 2004, 64, 135-139. [CrossRef]

8. Cacho, J.I.; Campillo, N.; Viñas, P.; Hernández-Córdoba, M. Dispersive liquid-liquid microextraction for the determination of nitrophenols in soils by microvial insert large volume injection-gas chromatography-mass spectrometry. J. Chromatogr. A 2016, 1456, 27-33. [CrossRef]

9. Deng, P.; Feng, J.; Xiao, J.; Liu, J.; Nie, X.; Li, J.; He, Q. Highly sensitive voltammetric sensor for nanomolar dopamine detection based on facile electrochemical reduction of graphene oxide and ceria nanocomposite. J. Electrochem. Soc. 2020, 167, 146511. [CrossRef]

10. Deng, P.; Nie, X.; Wu, Y.; Tian, Y.; Li, J.; He, Q. A cost-saving preparation of nickel nanoparticles/nitrogen-carbon nanohybrid as effective advanced electrode materials for highly sensitive tryptophan sensor. Microchem. J. 2021, 160, 105744. [CrossRef]

11. Ding, Z.; Deng, P.; Wu, Y.; Tian, Y.; Li, G.; Liu, J.; He, Q. A novel modified electrode for detection of the food colorant sunset yellow based on nanohybrid of $\mathrm{MnO}_{2}$ nanorods-decorated electrochemically reduced graphene oxide. Molecules 2019, 24, 1178. [CrossRef]

12. Wu, Y.; Deng, P.; Tian, Y.; Ding, Z.; Li, G.; Liu, J.; Zuberi, Z.; He, Q. Rapid recognition and determination of tryptophan by carbon nanotubes and molecularly imprinted polymer-modified glassy carbon electrode. Bioelectrochemistry 2020, $131,107393$. [CrossRef] [PubMed]

13. Feng, J.; Deng, P.; Xiao, J.; Tian, Y.; Wu, Y.; Liu, J.; Li, G.; He, Q. New voltammetric method for determination of tyrosine in foodstuffs using an oxygen-functionalized multi-walled carbon nanotubes modified acetylene black paste electrode. J. Food Compos. Anal. 2021, 96, 103708. [CrossRef]

14. Li, G.; Zhong, P.; Ye, Y.; Wan, X.; Cai, Z.; Yang, S.; Xia, Y.; Li, Q.; Liu, J.; He, Q. A highly densitive and stable dopamine sensor using shuttle-like $\alpha-\mathrm{Fe}_{2} \mathrm{O}_{3}$ nanoparticles/electro-reduced graphene oxide composites. J. Electrochem. Soc. 2019, 166, B1552-B1561. [CrossRef]

15. Wu, Y.; Deng, P.; Tian, Y.; Feng, J.; Xiao, J.; Li, J.; Liu, J.; Li, G.; He, Q. Simultaneous and sensitive determination of ascorbic acid, dopamine and uric acid via an electrochemical sensor based on PVP-graphene composite. J. Nanobiotechnol. 2020, 18, 112. [CrossRef]

16. He, Q.; Li, G.; Liu, X.; Liu, J.; Deng, P.; Chen, D. Morphologically tunable $\mathrm{MnO}_{2}$ nanoparticles fabrication, modelling and their influences on electrochemical sensing performance toward dopamine. Catalysts 2018, 8, 323. [CrossRef]

17. Wu, Y.; Deng, P.; Tian, Y.; Magesa, F.; He, Q. Construction of effective electrochemical sensor for the determination of quinoline yellow based on different morphologies of manganese dioxide functionalized graphene. J. Food Compos. Anal. 2019, 84, 103280. [CrossRef]

18. Tian, Y.; Deng, P.; Wu, Y.; Liu, J.; Li, J.; Li, G.; He, Q. High sensitive voltammetric sensor for nanomolarity vanillin detection in food samples via manganese dioxide nanowires hybridized electrode. Microchem. J. 2020, 157, 104885. [CrossRef]

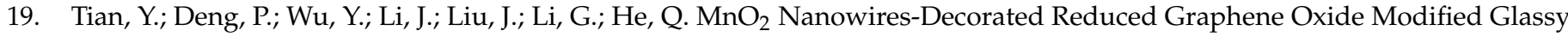
Carbon Electrode for Sensitive Determination of Bisphenol A. J. Electrochem. Soc. 2020, 167, 046514. [CrossRef]

20. Xu, X.; Liu, Z.; Zhang, X.; Duan, S.; Xu, S.; Zhou, C. $\beta$-cyclodextrin functionalized mesoporous silica for electrochemical selective sensor: Simultaneous determination of nitrophenol isomers. Electrochim. Acta 2011, 58, 142-149. [CrossRef]

21. Li, J.; Kuang, D.; Feng, Y.; Zhang, F.; Xu, Z.; Liu, M. A graphene oxide-based electrochemical sensor for sensitive determination of 4-nitrophenol. J. Hazard. Mater. 2012, 201-202, 250-259. [CrossRef]

22. Zeng, Y.; Zhou, Y.; Zhou, T.; Shi, G. A novel composite of reduced graphene oxide and molecularlyimprinted polymer for electrochemical sensing 4-nitrophenol. Electrochim. Acta 2014, 130, 504-511. [CrossRef]

23. Lupu, S.; Lete, C.; Marin, M.; Totir, N.; Balaure, P.C. Electrochemical sensors based on platinum electrodes modified with hybrid inorganic-organic coatings for determination of 4-nitrophenol and dopamine. Electrochim. Acta 2009, 54, 1932-1938. [CrossRef]

24. Huang, Y.; Bai, S.; Huang, J.; Ma, Y.; Zeng, Q.; Wang, M.; Wang, L. Simultaneous detection of nitrophenol isomers using an easy-to-fabricate thiophene-based microporous polymer film modified electrode. Microchem. J. 2020, 153, 104465. [CrossRef]

25. Deng, P.; Xu, Z.; Li, J. Simultaneous voltammetric determination of 2-nitrophenol and 4-nitrophenol based on an acetylene black paste electrode modified with a graphene-chitosan composite. Microchim. Acta 2014, 181, 1077-1084. [CrossRef] 
26. Deng, P.; Xu, Z.; Feng, Y.; Li, J. Electrocatalytic reduction and determination of p-nitrophenol on acetylene black paste electrode coated with salicylaldehyde-modified chitosan. Sensor. Actuators B Chem. 2012, 168, 381-389. [CrossRef]

27. He, Q.; Tian, Y.; Wu, Y.; Liu, J.; Li, G.; Deng, P. Facile and ultrasensitive determination of 4-nitrophenol based on acetylene black paste and graphene hybrid Electrode. Nanomaterials 2019, 9, 429. [CrossRef]

28. Ji, Y.; Li, Y.; Ren, B.; Liu, X.; Li, Y.; Soar, J. Nitrogen-doped graphene-ionic liquid-glassy carbon microsphere paste electrode for ultra-sensitive determination of quercetin. Microchem. J. 2020, 155, 104689. [CrossRef]

29. Ghanbari, M.H.; Norouzi, Z. A new nanostructure consisting of nitrogen-doped carbon nanoonions for an electrochemical sensor to the determination of doxorubicin. Microchem. J. 2020, 157, 105098. [CrossRef]

30. Jing, N.; Tian, M.; Wang, Y.; Zhang, Y. Nitrogen-doped carbon dots synthesized from acrylic acid and ethylenediamine for simple and selective determination of cobalt ions in aqueous media. J. Lumin. 2019, 206, 169-175. [CrossRef]

31. Wang, M.; Chen, K.; Liu, J.; He, Q.; Li, G.; Li, F. Efficiently enhancing electrocatalytic activity of $\alpha-\mathrm{MnO}_{2}$ nanorods/N-doped Ketjenblack carbon for oxygen reduction reaction and oxygen evolution reaction using facile regulated hydrothermal treatment Catalysts 2018, 8, 138. [CrossRef]

32. Han, R.; Ma, J.; Yang, C.; Cui, T.; Liu, W.; Wang, S. Synthesis of nitrogen-doped carbon nanocages for sensitive electrochemical detection of uric acid. Mater. Lett. 2019, 255, 126520. [CrossRef]

33. Liang, Y.; Lu, Y.; Xiao, G.; Zhang, J.; Chi, H.; Dong, Y. Hierarchical porous nitrogen-doped carbon microspheres after thermal rearrangement as high performance electrode materials for supercapacitors. Appl. Surf. Sci. 2020, 529, 147141. [CrossRef]

34. Zhang, W.; Bao, Y.; Bao, A. Preparation of nitrogen-doped hierarchical porous carbon materials by a template-free method and application to $\mathrm{CO}_{2}$ capture. J. Environ. Chem. Eng. 2020, 8, 103732. [CrossRef]

35. Zhang, H.; Ling, Y.; Peng, Y.; Zhang, J.; Guan, S. Nitrogen-doped porous carbon materials derived from ionic liquids as electrode for supercapacitor. Inorg. Chem. Commun. 2020, 115, 107856. [CrossRef]

36. Hussain, I.; Qi, J.; Sun, X.; Wang, L.; Li, J. Melamine derived nitrogen-doped carbon sheet for the efficient removal of chromium (VI). J. Mol. Liq. 2020, 318, 114052. [CrossRef]

37. Lei, W.; Han, L.; Xuan, C.; Lin, R.; Liu, H.; Xin, H.L.; Wang, D. Nitrogen-doped carbon nanofibers derived from polypyrrole coated bacterial cellulose as high-performance electrode materials for supercapacitors and Li-ion batteries. Electrochim. Acta 2016, 210, 130-137. [CrossRef]

38. Zhao, H.; Li, L.; Liu, Y.; Geng, X.; Yang, H.; Sun, C.; An, B. Synthesis and ORR performance of nitrogen-doped ordered microporous carbon by CVD of acetonitrile vapor using silanized zeolite as template. Appl. Surf. Sci. 2020, 504, 144438. [CrossRef]

39. Zhu, Y.; Yan, L.; Xu, M.; Li, Y.; Song, X.; Yin, L. Difference between ammonia and urea on nitrogen doping of graphene quantum dots. Colloids Surf. A 2020, 610, 125703. [CrossRef]

40. Zhang, D.; Wang, J.; Wang, Q.; Huang, S.; Feng, H.; Luo, H. Nitrogen self-doped porous carbon material derived from metalorganic framework for high-performance super-capacitors. J. Energy Storage 2019, 25, 100904. [CrossRef]

41. Wang, X.; Wang, W.; Qin, R.; Xu, D.; Li, Y.; Ou, A.; Lai, W.; Liu, Y.; Liu, X. Defluorination-assisted heteroatom doping reaction with ammonia gas for synthesis of nitrogen-doped porous graphitized carbon. Chem. Eng. J. 2018, 354, 261-268. [CrossRef]

42. Li, J.; Xu, Z.; Liu, M.; Deng, P.; Tang, S.; Jiang, J.; Feng, H.; Qian, D.; He, L. Ag/N-doped reduced graphene oxide incorporated with molecularly imprinted polymer: An advanced electrochemical sensing platform for salbutamol determination. Biosens. Bioelectron. 2017, 90, 210-216. [CrossRef] [PubMed]

43. Li, J.; Jiang, J.; Zhao, D.; Xu, Z.; Liu, M.; Deng, P.; Liu, X.; Yang, C.; Qian, D.; Xie, H. Facile synthesis of Pd/N-doped reduced graphene oxide via a moderate wet-chemical route for non-enzymatic electrochemical detection of estradiol. J. Alloys Compd. 2018, 769, 566-575. [CrossRef]

44. Mostazo-López, M.J.; Ruiz-Rosas, R.; Morallón, E. Nitrogen doped superporous carbon prepared by a mild method: Enhancement of supercapacitor performance. Int. J. Hydrogen Energy 2016, 41, 19691-19701. [CrossRef]

45. Raymundo-Piñero, E.; Cazorla-Amorós, D.; Linares-Solano, A. Structural characterization of N-containing activated carbon fibers prepared from a low softening point petroleum pitch and a melamine resin. Carbon 2002, 40, 597-608. [CrossRef]

46. Yamada, Y.; Kim, J.; Matsuo, S. Nitrogen-containing graphene analyzed by X-ray photoelectron spectroscopy. Carbon 2014, 70, 59-74. [CrossRef]

47. Nie, X.; Deng, P.; Zhang, R.; Tang, Z.; Wang, H.; Tang, Y. Nickel nanoparticles supported on nitrogen-doped carbon for vanillin detection. ACS Appl. Nano Mater. 2020, 3, 11791-11800. [CrossRef]

48. Wang, Y.; Qiao, M.; Mamat, X.; Hu, X.; Hu, G. Hierarchically ordered porous nitrogen doped carbon modified a glassy carbon electrode for voltammetry detection of quercetin. Mater. Res. Bull. 2021, 136, 111131. [CrossRef]

49. Qin, Q.; Brandi, F.; Badamdorj, B.; Oschatz, M.; Al-Naji, M. Preparation and functionalization of free-standing nitrogen-doped carbon-based catalyst electrodes for electrocatalytic $\mathrm{N}_{2}$ fixation. Mol. Catal. 2021, 515, 111935. [CrossRef]

50. Bard, A.J.; Faulkner, L.R. Electrochemical Methods: Fundamentals and Applications, 2nd ed.; John Wiley and Sons: New York, NY, USA, 2001.

51. Gooding, J.J.; Praig, V.G.; Hall, E.A.H. Platinum-catalyzed enzyme electrodes immobilized on gold using self-assembled layers. Anal. Chem. 1998, 70, 2396-2402. [CrossRef]

52. Zuman, P.; Fijalek, Z.; Dumanovic, D.; Suznjevic, D. Polarographic and electrochemical studies of some aromatic and heterocyclic nitro compounds, part I: General mechanistic aspects. Electroanalysis 1992, 4, 783-794. [CrossRef] 
53. Laviron, E.; Vallat, A.; Meunier-Prest, R. The reduction mechanism of aromatic nitro compounds in aqueous medium: Part V. The reduction of nitrosobenzene between $\mathrm{pH} 0.4$ and 13. J. Electroanal. Chem. 1994, 379, 427-435. [CrossRef]

54. Zuman, P.; Fijaiek, Z. Reaction of electrogenerated arylhydroxylamines and nitrosobenzene in the course of reduction of nitrobenzene under conditions of cyclic voltammetry. J. Electroanal. Chem. Interfacial Electrochem. 1990, 296, 589-593. [CrossRef]

55. Deng, P.; Xiao, J.; Feng, J.; Tian, Y.; Wu, Y.; Li, J.; He, Q. Highly sensitive electrochemical sensor for tyrosine detection using a sub-millimeter electrode. Microchem. J. 2021, 165, 106106. [CrossRef]

56. Deng, P.; Feng, J.; Wei, Y.; Xiao, J.; Li, J.; He, Q. Fast and ultrasensitive trace malachite green detection in aquaculture and fisheries by using hexadecylpyridinium bromide modified electrochemical sensor. J. Food Compos. Anal. 2021, 102, 104003. [CrossRef]

57. Deng, P.; Feng, J.; Xiao, J.; Wei, Y.; Liu, X.; Li, J.; He, Q. Application of a simple and sensitive electrochemical sensor in simultaneous determination of paracetamol and ascorbic Acid. J. Electrochem. Soc. 2021, 168, 096501. [CrossRef] 